\title{
RESEARCH
}

Open Access

\section{CD157 in bone marrow mesenchymal stem cells mediates mitochondrial production and transfer to improve neuronal apoptosis and functional recovery after spinal cord injury}

Jing $\mathrm{Li}^{1}$, Heyangzi $\mathrm{Li}^{1}$, Simin $\mathrm{Cai}^{1}$, Shi Bai ${ }^{2}$, Huabo Cai ${ }^{3^{*}}$ and Xiaoming Zhang ${ }^{1,3^{*}}$

\begin{abstract}
Background: Recent studies demonstrated that autologous mitochondria derived from bone marrow mesenchymal stem cells (BMSCs) might be valuable in the treatment of spinal cord injury (SCl). However, the mechanisms of mitochondrial transfer from BMSCs to injured neurons are not fully understood.

Methods: We modified BMSCs by CD157, a cell surface molecule as a potential regulator mitochondria transfer, then transplanted to SCI rats and co-cultured with OGD injured VSC4.1 motor neuron. We detected extracellular mitochondrial particles derived from BMSCs by transmission electron microscope and measured the CD157/cyclic ADP-ribose signaling pathway-related protein expression by immunohistochemistry and Western blotting assay. The CD157 ADPR-cyclase activity and Fluo-4 AM was used to detect the $\mathrm{Ca}^{2+}$ signal. All data were expressed as mean \pm SEM. Statistical analysis was analyzed by GraphPad Prism 6 software. Unpaired t-test was used for the analysis of two groups. Multiple comparisons were evaluated by one-way ANOVA or two-way ANOVA.

Results: CD157 on BMSCs was upregulated when co-cultured with injured VSC4.1 motor neurons. Upregulation of CD157 on BMSCs could raise the transfer extracellular mitochondria particles to VSC4.1 motor neurons, gradually regenerate the axon of VSC4.1 motor neuron and reduce the cell apoptosis. Transplantation of CD157-modified BMSCs at the injured sites could significantly improve the functional recovery, axon regeneration, and neuron apoptosis in SCl rats. The level of $\mathrm{Ca}^{2+}$ in CD157-modified BMSCs dramatically increased when objected to high concentration CADPR, ATP content, and MMP of BMSCs also increased.

Conclusion: The present results suggested that CD157 can regulate the production and transfer of BMSC-derived extracellular mitochondrial particles, enriching the mechanism of the extracellular mitochondrial transfer in BMSCs transplantation and providing a novel strategy to improve the stem cell treatment on SCl.
\end{abstract}

Keywords: Spinal cord injury, Bone marrow stromal cells, Mitochondria, CD157, Calcium

\footnotetext{
*Correspondence: maggiechb@126.com; zxm@zju.edu.cn

${ }^{3}$ Department of Emergency Medicine, Sir Run Run Shaw Hospital; School of Medicine, Zhejiang University, Hangzhou 310058, China

'Department of Anatomy, School of Medicine, Zhejiang University, Hangzhou 310058, China

Full list of author information is available at the end of the article
}

(C) The Author(s). 2021 Open Access This article is licensed under a Creative Commons Attribution 4.0 International License, which permits use, sharing, adaptation, distribution and reproduction in any medium or format, as long as you give appropriate credit to the original author(s) and the source, provide a link to the Creative Commons licence, and indicate if changes were made. The images or other third party material in this article are included in the article's Creative Commons licence, unless indicated otherwise in a credit line to the material. If material is not included in the article's Creative Commons licence and your intended use is not permitted by statutory regulation or exceeds the permitted use, you will need to obtain permission directly from the copyright holder. To view a copy of this licence, visit http://creativecommons.org/licenses/by/4.0/ The Creative Commons Public Domain Dedication waiver (http://creativecommons.org/publicdomain/zero/1.0/) applies to the data made available in this article, unless otherwise stated in a credit line to the data. 


\section{Introduction}

Spinal cord injury (SCI) is a devastating disease with complex secondary pathological complications and it still has no effective treatment. SCI causes a series of complex pathological changes, including ischemia [1, 2], oxidative stress [3], neuroinflammation [4], axonal demyelination and degeneration [5], apoptosis [6], and spinal cord injury-induced immune deficiency syndrome after initial trauma [7, 8]. Furthermore, spinal cord injury-induced immune deficiency syndrome, excessive inflammatory responses [9], ionic homeostasis loss [10, 11], the upregulated release of excitatory amino acids, and the excess excitatory amino acid receptor activation can cause secondary injury cascades after SCI [12]. The study aimed to determine the neuron recovery and axon regeneration for spinal cord injury treatment.

The mitochondrion is one of the most important and studied subcellular organelles and its morphology and function are greatly influenced by secondary injury after SCI [13]. Mitochondria function and morphology changes, including irregular shape, enlarged size, disordered cristae, fusion and fission, reduced membrane potential, and expression changes of related proteins occur in the acute phase after SCI. Furthermore, these morphological and functional changes regulate underlying secondary injury processes, such as necrosis, apoptosis, and autophagy [14]. Mitochondrial dysfunction influences secondary injury development and neuronal cell death $[13,15]$. Therefore, restoring the mitochondria function could be a potential therapeutic SCI strategy.

Bone marrow mesenchymal stem cells (BMSCs) from bone marrow with excellent capacity to differentiate into multiple cell lineages have served as an ideal tool for our SCI studies [16]. Of late, BMSCs have been frequently used for transplantation studies because they are easy to harvest, culture, expand, and modulate in vitro [17, 18]. BMSCs have various characteristics hence their versatility in the injured tissue' repair mechanisms [19]. For example, BMSCs can improve bone regeneration to repair lost bone [20] and differentiate into cardiomyocytes [21]. Our previous studies found that BMSCs transplantation after SCI improved locomotor function in SCI rats, alleviated pathological deterioration through mitochondria transfer, and decreased ER stress-induced neuronal apoptosis and its related factors [22].

CD157 (bst-1, bone marrow stromal antigen-1) is a cell surface molecule expressed in myeloid, endothelial, mesothelial, and epithelial ovarian cancer cells, and acts as an ectoenzyme and a signaling receptor [23]. CD157 is also capable of signal transduction [24]. Reports have shown that CD157 promotes pre-T cell expansion [25] and regulates leukocyte trafficking [26] and ovarian cancer progression [22]. It is also involved in humoral immune responses [27], neutrophil transmigration [28], and hematopoietic stem cell support [29]. Besides, CD157 (a member of the NADase/ADP-ribosyl cyclase family) has been reported to induce cyclic ADP-ribose catalysis in embryonic and adult nervous systems [30]. This study hypothesized that CD157 regulates mitochondria transfer from BMSCs to injured neurons after $\mathrm{SCI}$ and promotes motor function recovery and axon regeneration via the CD157/cADPR/calcium signaling pathway.

\section{Materials and methods \\ Animals}

Male Sprague-Dawley rats sacrificed for this study. All experimental procedures were approved by the Animal Ethics Committee of Zhejiang University and followed the National Institutes of Health guidelines strictly. Animals were housed under a 12-h light/dark cycle with free access to food and water. All efforts were made to minimize the number of animals used and their suffering. The individual mouse was considered the experimental unit within the studies.

\section{Primary BMSCs isolation, culture, and characterization}

Primary BMSCs were isolated from the femurs of 3-4 week old Sprague-Dawley male rats following our previous study. BMSCs were cultured in Dulbecco's modified Eagle medium: Nutrient Mixture F-12 (DMEM/F-12) with $10 \%$ fetal bovine serum, $100 \mathrm{U} / \mathrm{ml}$ penicillin and $100 \mathrm{U} / \mathrm{ml}$ streptomycin, and medium were changed every 2 days. The fluorescence-activated cell sorting (FACS) analysis was adopted to characterize BMSCs in our previous study [31].

\section{Construction of adenovirus and infection of BMSCs}

The CD157 overexpression vector was constructed with pHBAD-EF1-MCS-3flag-CMV-GFP vector. The MCS segment was inserted bst-1 gene, and the EF1 promoter regulated the expression of bst- 1 gene and the CMV promoter regulated EGFP. Meanwhile, pHBAd-U6-MCS-CMV-GFP was used to construct CD157 interference vector that contained a U6 promoter which regulated the expression of shRNA of bst-1 inserted in the EcoR I and BamH I sites and a CMV promoter regulated the expression of GFP gene. A vector only expressing GFP gene was used to be the control. All vectors were synthesized by the Han Bio Co. LTD (Shanghai, China).

The BMSCs were infected at a 50 multiplicity of infection with the adenovirus vectors after the polybrene $(5 \mu \mathrm{g} / \mathrm{ml})$ treatment for $30 \mathrm{~min}$. Forty-eight hours later, the infected BMSCs were observed with fluorescence microscope (Olympus Corp., Tokyo, Japan) and the Western blotting analysis was applied to detect the expression of CD157. 


\section{Oxygen-glucose deprivation (OGD) and re-oxygenation of VSC4.1 motor neurons}

The ventral spinal cord 4.1 (VSC4.1) motor neuron cells were cultured in RPMI 1640 medium with 10\% (V/V) fetal bovine serum and $100 \mathrm{U} / \mathrm{m}$ penicillin and streptomycin at $37{ }^{\circ} \mathrm{C}$ with $5 \% \mathrm{CO}_{2}$ in a fully humidified incubator. OGD and re-oxygenation models were used to mimic ischemia and hypoxia in SCI. In brief, VSC4.1 motor neurons were cultured in D-Hanks' balanced salt solution without glucose in a sealed hypoxic GENbag fitted with a AnaeroPack (MGC, Japan) to scavenge free oxygen and the Non-OGD group was cultured in Hanks' balanced salt solution containing the normal concentration of glucose with $5 \% \mathrm{CO}_{2}$ for $8 \mathrm{~h}$. Later, all cells were re-oxygenated and cultured in normal complete medium or were co-cultured with BMSCs. All duration were determined by our previous study [32].

\section{$\mathrm{SCl}$ model and BMSCs transplantation}

Twenty-four Sprague-Dawley male rats weighing 200$220 \mathrm{~g}$ were divided into four groups randomly, by using the standard $=$ RAND() function in Microsoft Excel. SCI was performed with Allen's method in accordance with our previous study. In brief, all rats were anesthetized with pentobarbital $(40 \mathrm{mg} / \mathrm{kg}$, i.p.). Then, their vertebral columns were exposed, and laminectomy was operated at the T10 spinal vertebra. A weight of $10 \mathrm{~g}$ was dropped from a height of $50 \mathrm{~mm}$ on the exposed spinal cord. The impounder was left for $20 \mathrm{~s}$ to produce a moderate contusion. Immediately, the $10 \mu \mathrm{l}$ culture medium containing $10^{6}$ BMSC+MOCK, BMSC+Over, or BMSC+shRNA were injected into the epicenter of the injured spinal cord using an electrode microneedle as the $\mathrm{SCI}+\mathrm{MOCK}$ group, $\mathrm{SCI}+$ Over group, and $\mathrm{SCI}+$ shRNA group respectively. Meanwhile, the control rats received the sham operation with the same surgical procedure without injury, while the SCI group received the same dose of DMEM.

\section{Collection of BMSC-conditioned medium (BCM)}

BMSCs were planted at $1 \times 10^{5}$ cells/dish and cultured in DMEM/F12 complete medium. When attached, the cells were washed with phosphate-buffered saline (PBS) for three times and incubated in high glucose Dulbecco's modified Eagle medium (DMEM) without serum to stimulate the production of extracellular mitochondria particles. The medium was collected $24 \mathrm{~h}$ later. BMSCconditioned medium (BCM) was treated by filtering through a $1.2-\mu \mathrm{m}$ syringe filter or by spinning cell debris down with centrifuging at $2000 \times g$ for $10 \mathrm{~min}$. Meanwhile, BCM was filtrated through a $0.22-\mu \mathrm{m}$ syringe filter to prepare mitochondria deleted medium (Md-BCM) that contains no extracellular mitochondria particles.
MitoTracker red staining

BMSCs were stained with $200 \mathrm{nM}$ MitoTracker Red CMXRos (Molecular Probes, M7512, Invitrogen, USA) for $30 \mathrm{~min}$ at $37^{\circ} \mathrm{C}$ to label the intracellular mitochondria. The cells were washed three times with PBS to exclude the interference of excessive dye.

\section{Carboxyfluorescein succinimidyl ester (CFSE)-fluorescent label}

Attached VSC4.1 motor neurons were stained by $10 \mu \mathrm{M}$ carboxyfluorescein succinimidyl ester (CFSE, \#C1031, green color, Beyotime Institute of Biotechnology, China) for $30 \mathrm{~min}$ in $37^{\circ} \mathrm{C}$ and washed by PBS for three times.

\section{Co-culture of post-OGD VSC4.1 motor neurons with BMSCs}

VSC4.1 motor neurons were cultured directly with BMSCs in 10-cm dishes or in the 6-well 8- $\mu \mathrm{m}$ transwell system (Corning, USA) in a 1:1 ration. All co-culture system last for $24 \mathrm{~h}$.

\section{Microscope observation}

The observation of extracellular mitochondria particles derived from BMSCs was carried out by transmission electron microscopy in accordance with previous study [33]. VSC4.1 motor neurons were cultured in $1 \times 10^{5}$ cell/well with round coverslips and fixed with $0.5 \%$ paraformaldehyde after co-culturing. 4',6-Diamidino-2-phenylindole (DAPI, blue color, \#C1002, Beyotime Institute of Biotechnology, China) was applied to all cells to label nucleus after fixing. The internalization of extracellular mitochondria (red color) derived from BMSCs in cocultured VSC4.1 motor neurons (green color) was captured by fluorescence microscope. To detect the regeneration of motor neuron axons, optical microscope was used to observe the length and the number of axons.

\section{Western blot analysis}

Western blot was performed to determine the transfection efficiency of vectors and the expression level of proteins related to cellular apoptosis and mitochondrial apoptosis. Each sample was detected concentration and loaded onto 4-12\% Bis-Tris gels (M00653, GeneScript, China). After the electorophoresis and transferred to PVDF membranes, the membranes were blocked in Tris-buffered saline containing 0.1\% Tween 20 (TBST) and 5\% skim milk (232100, BD, USA) for $90 \mathrm{~min}$ at room temperature. Membranes were washed with TBST and then incubated overnight at $4{ }^{\circ} \mathrm{C}$ with anti-GAPDH (1:2000, 10494-1-AP, Proteintech, USA) and anti-Bone marrow stromal cell antigen 1 (CD157) antibody (1, 1000, ab208442, Abcam, USA). After being washed with TBST, membranes were incubated with infrared-labeled peroxidase-conjugated secondary antibodies for $1 \mathrm{~h}$ at 
room temperature. Bands were captured and quantificated by Odyssey CLx Image Studio (Gene Ltd., USA).

\section{Immunofluorescence staining}

$0.5 \%$ paraformaldehyde fixed cells or frozen spinal cord sections were washed 3 times in $1 \times$ PBS and blocked in blocking buffer for $60 \mathrm{~min}$. Then, cells or spinal cord sections were incubated overnight at $4{ }^{\circ} \mathrm{C}$ with primary antibody as follows: rabbit anti-Grp 78 antibody (1:200, ER40402, HuaBio, CN), rabbit anti-NF-kB p65 antibody (1:200, ab16502, Abcam, USA), GAP 43 (D9C8) rabbit mAb (1:200, \#8945, CST, USA), Bcl-xL (54H6) rabbit mAb (1:200, \#2764, CST, USA), and AKT (phospho Thr308) antibody (1:50, om238718, Omnimabs, USA). After washing by PBS 3 times, fluorescent secondary antibodies incubated for $2 \mathrm{~h}$ at room temperature. Finally, DAPI was added to visualize the nucleus, and coverslips were placed

\section{Potential of mitochondrion measurement}

The mitochondrial membrane potential (MMP) assay kit with JC-1 (C2006, Beyotime Institute of Biotechnology, China) was used to assess mitochondrial membrane potential to detect whether the extracellular mitochondrion still had function. BCM and $\mathrm{Md}-\mathrm{BCM}$ were collected and mixed with $\mathrm{JC} 1(5 \mu \mathrm{M})$ for $30 \mathrm{~min}$ at $37^{\circ} \mathrm{C}$. When the membrane potential of mitochondria completely lost, green fluorescence (Ex $485 \mathrm{~nm}$ Em $516 \mathrm{~nm}$ ) would be observed and the normal cells stained should show red fluorescence (Ex $579 \mathrm{~nm} / \mathrm{Em} 599 \mathrm{~nm}$ ). MMP was determined by the Varioskan Flash microplate reader.

\section{ATP measurement}

Adenosine triphosphate (ATP) level was determined by CellTiter-Glo luminescence (G7570, Promega, USA). For intracellular ATP content, cells were incubated by $200 \mu \mathrm{l}$ reagent buffer each well, standing for $30 \mathrm{~min}$ at room temperature for lysing cells. For extracellular ATP, the culture medium was collected and centrifuged at $2000 \times g$ for $10 \mathrm{~min}$. Then, the supernatant was collected and centrifuged at $20,000 \times g$ for $20 \mathrm{~min}$ at $4{ }^{\circ} \mathrm{C}$, with the remaining lower half to use. CellTiter-Glo luminescence test solution $(50 \mu \mathrm{l})$ was added into culture media $(50 \mu \mathrm{l})$ and incubated for $30 \mathrm{~min}$ at room temperature in opaque-walled 96-well plates. Luminescent signal was determined by the microplate reader.

\section{FACS analysis on the content of extracellular} mitochondria particles

FACS analysis was performed by BD Fortessa or CytoFLEX LX. BCM were prepared and collected as described as before. Two hundred-nanometer and 300-nm diameter calibration particles, DMEM media incubating unstained BMSCs, and DMEM media were used to control for determining appropriate gates, voltages, and compensations required in multivariate flow cytometry.

\section{Determination of CD157/ADPR-cyclase activity}

ADPR-cyclase activity was determined with nicotinamide guanine dinucleotide $\left(\mathrm{NGD}^{+}\right)$(N5131, Sigma, USA) as the substrate as described before [34]. Briefly, BMSCs were cultured in 96-well plate with $200 \mu \mathrm{l}$ complete DMEM/F12 medium. After attaching, BMSCs were incubated with $500 \mu \mathrm{M} \mathrm{NGD}{ }^{+}$in $0.1 \mathrm{M}$ PBS (pH 7.2 ) at $37^{\circ} \mathrm{C}$ for $10 \mathrm{~min}$, and the production was determined at excitation/emission wavelengths of Ex $290 \mathrm{~nm} /$ $\mathrm{Em} 410 \mathrm{~nm}$ with the microplate reader.

\section{$\mathrm{Ca}^{2+}$ signal detection}

To explore whether the CD157/cADPR mechanism was $\mathrm{Ca}^{2+}$ dependent, the level of $\mathrm{Ca}^{2+}$ in BMSCs was determined by Fluo-4 AM (S1060, Beyotime Institute of Biotechnology, China). BMSCs were incubated in 96well plates with $2 \mu \mathrm{M}$ Fluo- 4 AM for $30 \mathrm{~min}$ at room temperature. After washing with PBS for three times, fluorescence intensity was determined by the Varioskan Flash microplate reader at excitation/emission wavelengths of Ex $488 \mathrm{~nm} / \mathrm{Em} 516 \mathrm{~nm}$.

\section{Assessment of motor function}

Basso, Beattie, and Bresnahan (BBB) locomotor scales were used to assess the recovery of rats' motor function. The scores were obtained by two independent examiners who were blind to the four groups. All rats were observed and assessed the relevant indicators of hind limb motor function and physical control function in an open field for $3 \mathrm{~min}$ at 1, 7, 14, 21, and 28 days post-surgery.

\section{Statistical analysis}

All data were expressed as mean \pm SEM. Statistical analysis was analyzed by GraphPad Prism 6 software. Unpaired $t$-test was used for the analysis of two groups. Multiple comparisons were evaluated by one-way ANOVA or two-way ANOVA. $P<0.05$ was considered to be statistically significant.

\section{Results}

Production and transfer of BMSC-derived mitochondria MitoTracker Red CMXRos was employed to visualize the mitochondria of BMSCs (Fig. 1a). BMSC conditionedmedium (BCM) was collected and concentrated after $24 \mathrm{~h}$ of pre-staining. A transmission electron microscopy was used to observe extracellular mitochondria in BCM. The images showed that partial extracellular mitochondria maintained their normal morphology and structure (Fig. 1b). A previous study showed that the extracellular mitochondria or particle sizes ranged between 300 and $1100 \mathrm{~nm} 48$. Therefore, we used $0.22 \mu \mathrm{m}$ filters to deplete 

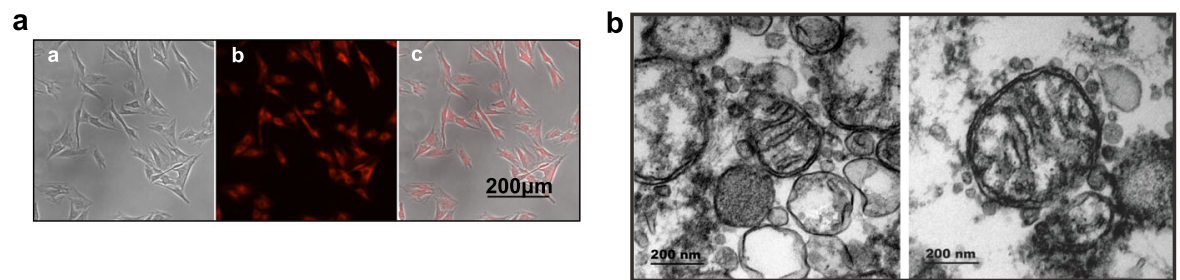

C
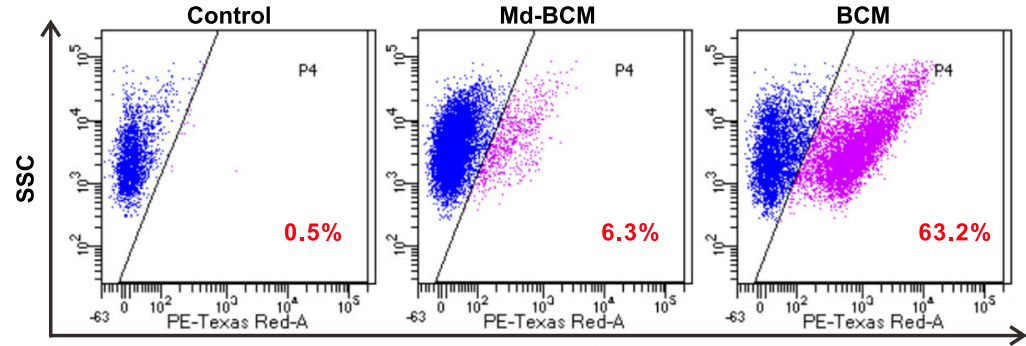

Mito Tracker red CMXRos

d

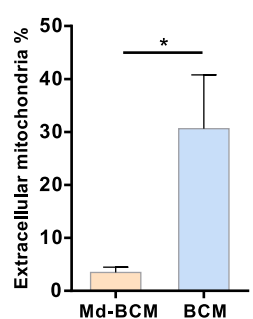

e

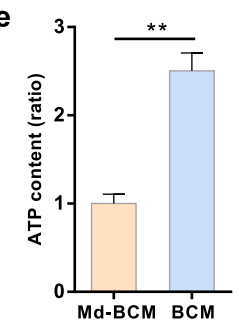

f

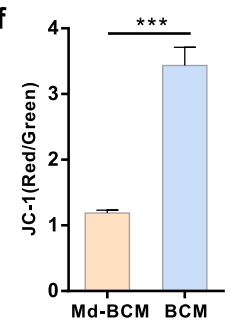

g

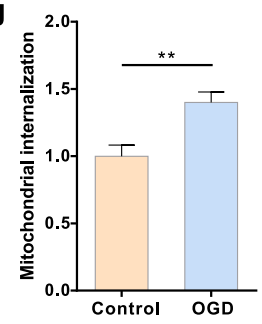

h
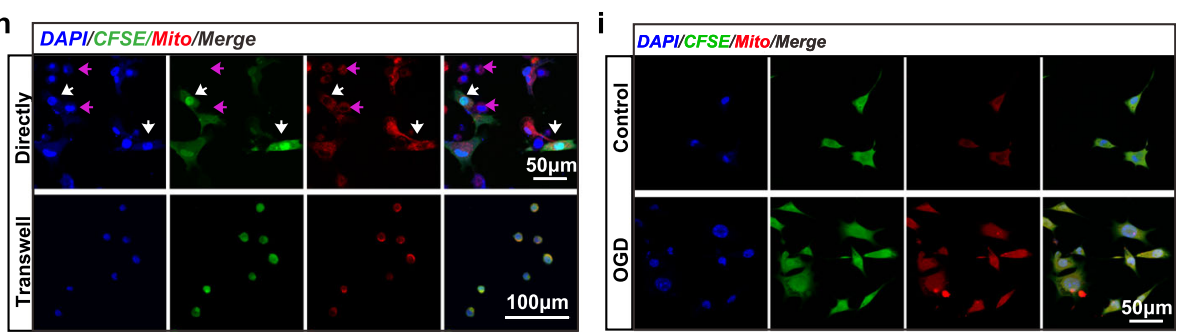

Fig. 1 BMSCs produce functional extracellular mitochondria particles transferred into neurons. a Mitochondria in BMSCs visualized using Mito Tracker Red CMXRos. The red dots represent mitochondria. Scale bar, $200 \mu \mathrm{m}$. b Representative TEM images of extracellular mitochondria derived from BMSCs. Scale bar, $200 \mathrm{~nm}$. c FACS results of extracellular mitochondria particles pre-stained using Mito Tracker Red CMXRos. Control group, BMSC medium without staining. Md-BCM group, the mitochondria depleted medium; BCM group, the normal pre-stained medium. $\mathbf{d}$ Extracellular mitochondria ratio in medium $(n=5) .{ }^{*} p<0.05$. e Quantification of ATP content in medium $\left(n=6\right.$, fold of Md-BCM). ${ }^{*} p<0.01$. f Statistics for extracellular mitochondria membrane potential $(n=8) .{ }^{* *} p<0.001$. g Quantification of internalized mitochondria in VSC4.1 motor neurons w/o OGD (fold of control). Image J was used to measure IOD. ${ }^{* *} p<0.01$. h Representative fluorescence images of internalized mitochondria in VSC4.1 motor neurons co-cultured with BMSCs. In the directly group, BMSCS were pre-stained using CFSE. The purple arrows indicate VSC4.1 motor neurons and the white arrows indicate co-cultured BMSCs. Scale bar, $50 \mu \mathrm{m}$. In the transwell system, VSC4.1 motor neurons were pre-stained using CFSE. Scale bar, $100 \mu \mathrm{m}$. i Representative fluorescence images of VSC4.1 motor neurons. All VSC4.1 motor neurons were co-cultured with BMSCs in the transwell system. Control group, normal VSC4.1 motor neurons; OGD group, VSC4.1 motor neurons with oxygen and glucose deprivation treatment. Scale bar, $50 \mu \mathrm{m}$

$\mathrm{BCM}$ mitochondria to obtain the mitochondria deleted medium (Md-BCM) and then collected BCM and Md$\mathrm{BCM}$ and used FACS to determine mitochondria particle content. The results showed that BCM contained a certain amount of mitochondria particles derived from BMSCs than Md-BCM (Fig. 1c, d).

We further determined the ATP content and JC-1 assay to assess the extracellular mitochondria function. Notably, when the mitochondria in extracellular particles were removed, ATP levels decreased (Fig. 1e) and MMP sharply declined when the mitochondria in extracellular particles were removed (Fig. 1f), indicating that the mitochondria are functional in the extracellular particles.

We used MitoTracker Red CMXRos to pre-stained mitochondria and CFSE to pre-stained intracellular matrix to double-stain BMSCs. BMSCs were directly cocultured with VSC4.1 motor neurons in a 1:1 ratio for 
24h. Meanwhile, the MitoTracker Red CMXRos prestained BMSCs were seeded in transwell inserts and cocultured with CFSE pre-stained VSC4.1 motor neurons in a transwell system. We then used fluorescence microscopy to confirm if the derived mitochondrion was successfully transferred into VSC4.1 motor neurons. The red spots indicated that BMSCs could produce and transfer extracellular mitochondria particles and that the mitochondria particles could be seized and initialized by VSC4.1 motor neurons (Fig. 1h). We also co-cultured BMSCs with pre-stained VSC4.1 motor neurons w/o OGD treatment and found that mitochondrial internalization in VSC4.1 motor neurons significantly increased after OGD treatment (Fig. 1g, i).

\section{CD157 expressions in BMSCs and VSC4.1 motor neurons}

CD157 is expressed in both BMSCs and VSC4.1 motor neurons. We assumed that CD157 is involved in the transfer of extracellular mitochondria. However, further investigations are needed to determine whether CD157 expressions in BMSC, VSC, or both are involved in the extracellular mitochondria transfer. We used an immunofluorescence assay to determine CD157 expressions in the co-cultured BMSCs and VSC4.1 motor neurons w/o OGD. CD157 was visualized using an antiCD157 antibody (Fig. 2a) and Image J was used to measure integrated optical density (IOD). There was no difference in CD157 expressions between OGD and normal VSC4.1 motor neurons (Fig. 2b). However, CD157 was significantly increased on BMSCs co-cultured with OGD VSC4.1 motor neurons compared with the BMSCs co-cultured with normal VSC4.1 motor neurons (Fig. 2c). These results indicated that $\mathrm{CD} 157$ expression in BMSCs could be involved in the regulation of BMSCderived mitochondria production and transfer. Therefore, we constructed the bst-1+ and bst-1- adenovirus vector and observed all vectors titers using a fluorescence microscope (Fig. 2d). CD157 expression was examined using western blotting (Fig. 2e).

\section{Effect of CD157 on BMSC-derived extracellular mitochondria production and transfer}

We transfected BMSCs with Mock vector, overexpressed CD157 vector, and CD157 interference vectors, represented as Mock group, Over group, and shRNA group, respectively. We used pre-stained Mock, Over, and shRNA groups, as unstained BMSC groups and DMEM blank group as the control. All the BMSC conditionedmedium were collected and filtered using a $1.2-\mu \mathrm{m}$ filter. FACS results (Fig. 3a, b) and OD value (Fig. 3c) showed that the extracellular mitochondria production was significantly upregulated in the Over group compared with
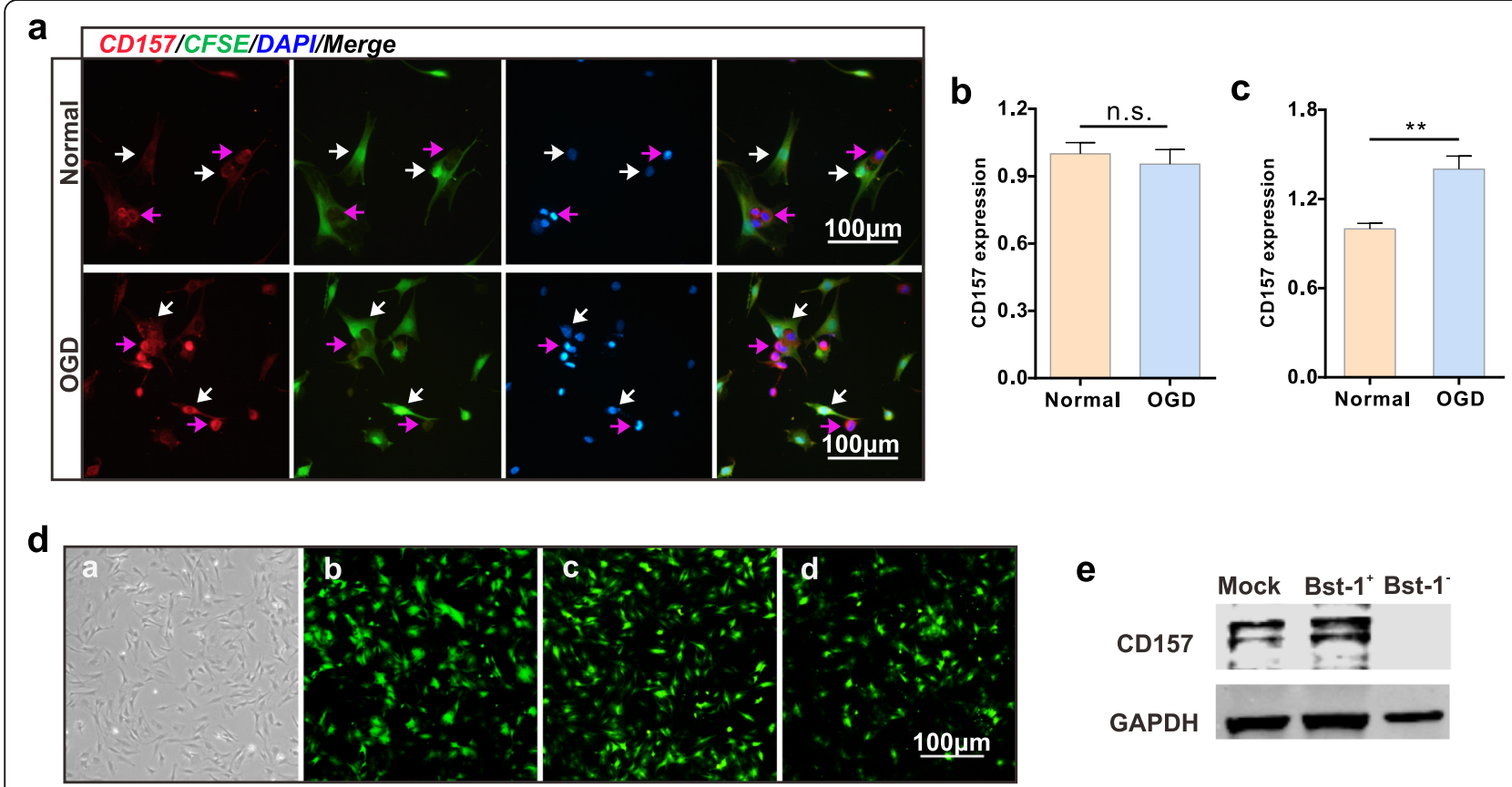

Fig. 2 Effect of upregulated CD157 expression on BMSCS and VSC4.1 motor neurons. a Representative immunofluorescence images of CD157 protein. BMSCs were pre-stained using CFSE. Normal group, cells without any treatment; OGD group, VSC4.1 motor neurons were treated with oxygen and glucose deprivation for $8 \mathrm{~h}$ before co-cultured with BMSCs. The purple arrows indicate VSC4.1 motor Scale bars, 100 um. b, c CD157 expression quantification (fold of normal) of VSC4.1 motor neurons (b) and BMSCs (c). Image J was used to measure IOD. n.s., non-significant,

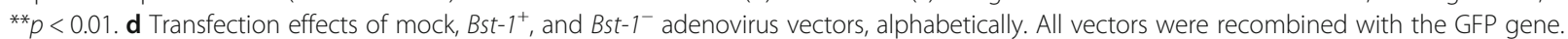
Scale bar, $100 \mu \mathrm{m}$. e Western blotting of CD157 protein expression of transfected BMSCs 

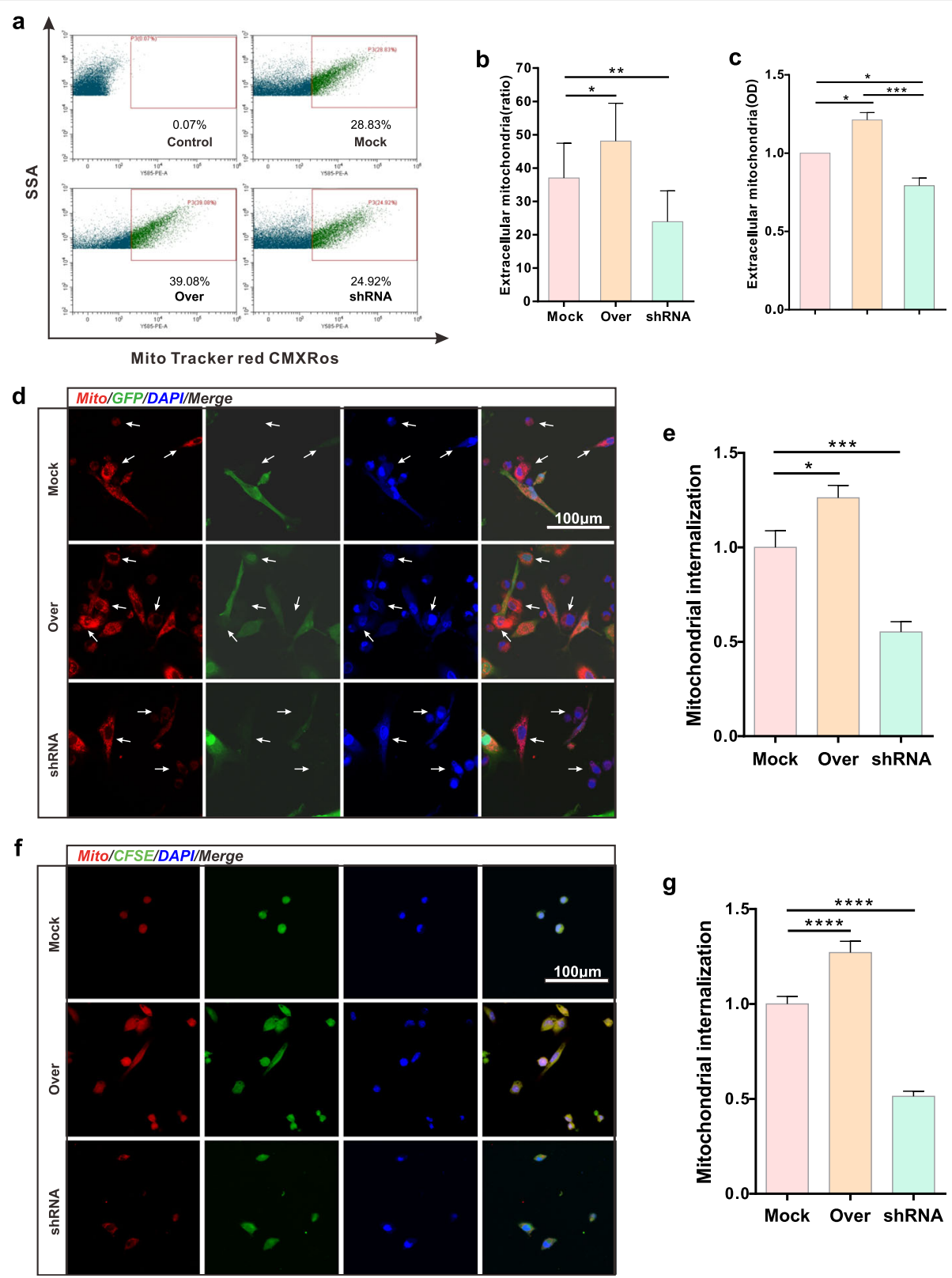

Fig. 3 CD157 overexpression in BMSCs enhances extracellular mitochondria production and transfer. a FACS results of extracellular mitochondria from various transfected BMSCs. Control, BMSCs without pre-staining. $\mathbf{b}$ Extracellular mitochondria particle ratio detected by FACS $(n=4)$. ${ }^{*} p<$ $0.05,{ }^{* *} p<0.01$. c Extracellular mitochondria particle quantification detected by Varioskan Flash $(n=5) .{ }^{*} p<0.05,{ }^{* * *} p<0.001$. d Representative confocal images of internalized mitochondria of VSC4.1 motor neurons. All VSC4.1 motor neurons were subjected to OGD treatment before direct co-culture with BMSCs. Transfected BMSCs were marked using GFP. The white arrows indicate VSC4.1 motor neurons. Scale bars, $100 \mu \mathrm{m}$. f Representative confocal images of internalized mitochondria of VSC4.1 motor neurons. OGD VSC4.1 motor neurons co-cultured with BMSCs in transwell system. VSC4.1 motor neurons were pre-stained using CFSE. Scale bars, $100 \mu \mathrm{m}$. e, g Mitochondria internalization quantification of VSC4.1 motor neurons (fold of Mock group). c Direct co-culture and e transwell co-culture. Image J was used to measure IOD. ${ }^{*} p<0.05$, ${ }^{* * *} p<0.001,{ }^{* * *} p<0.0001$

the Mock group. Conversely, extracellular mitochondria production was downregulated in the shRNA group. Analysis of mitochondrial internalization via direct coculture (Fig. 3d, e) and transwell co-culture (Fig. 3f, g) showed that mitochondria-derived from the Over group was highly internalized by injured VSC4.1 motor neurons compared with the Mock group. However, the shRNA group had a low level. Therefore, CD157 overexpression in BMSCs can upregulate BMSC-derived extracellular mitochondria particle production and transfer. 
Effects of CD157 on OGD VSC4.1 motor neurons in vitro OGD-treated VSC4.1 motor neurons were co-cultured for $24 \mathrm{~h}$ with transfected BMSCs in the transwell system. We used an optical microscope (Fig. 4a) for visualization and found that CD157 expression levels in BMSCs did not affect the number of neurites (Fig. 4b). Besides, CD157 overexpression promoted the neurites' length regeneration (Fig. 4c). Therefore, CD157 overexpression in BMSCs promotes neurite outgrowth of VSC4.1 motor neuron length and not their number.

Immunofluorescence staining was used to detect the expression of apoptosis and inflammation-related proteins, including Grp78, NF- $\mathrm{kB}$, and Bcl-xl. Results showed that Grp 78 (Fig. 4d, h) and NF-kB expressions
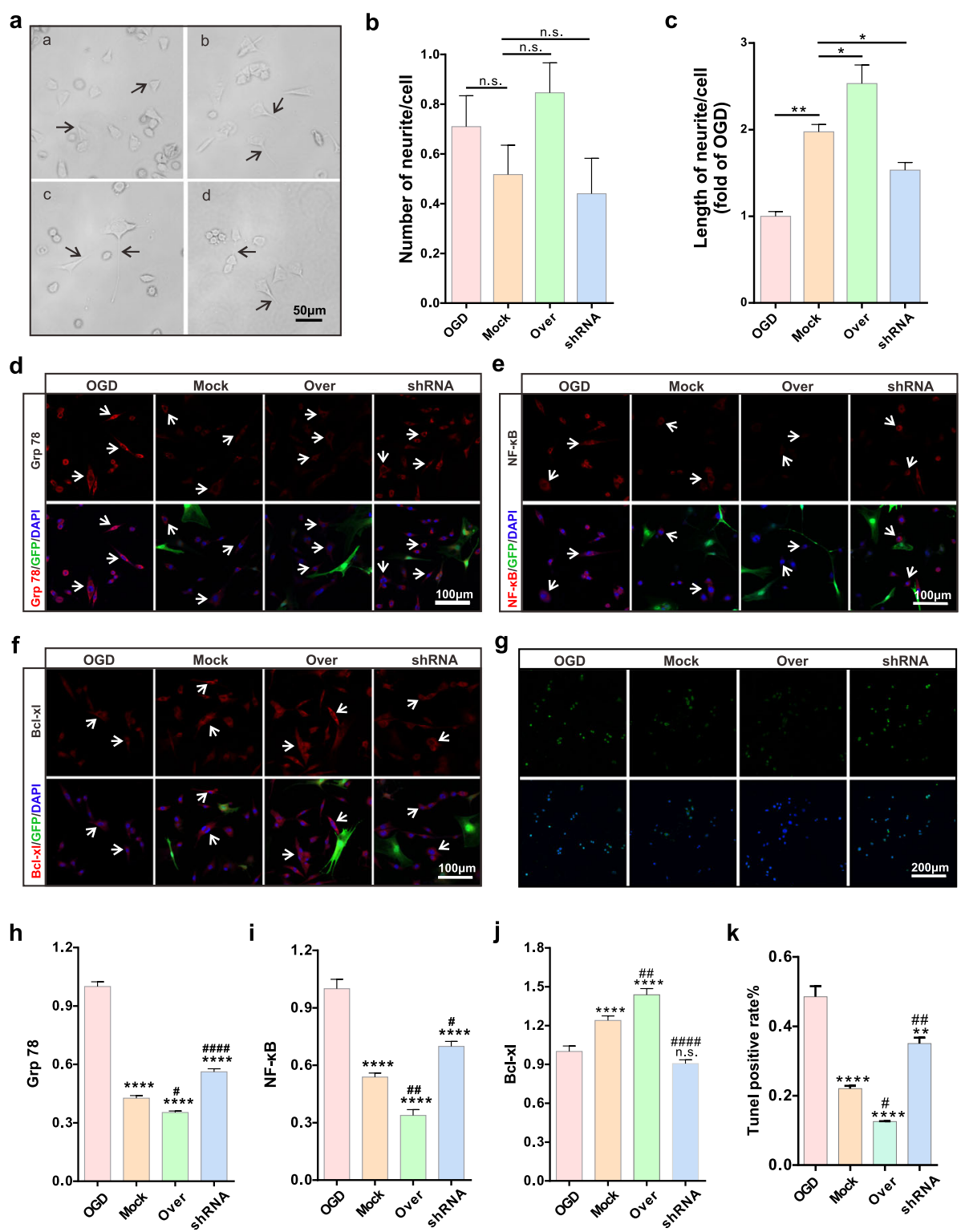

Fig. 4 CD157 overexpression in BMSCs improves the injured VSC4.1 motor neurons in vitro. a Representative images of recovered VSC4.1 motor neurons. The four groups are in alphabetical order: OGD group, Mock group, Over group, and shRNA group. The black arrows show the axons. Scale bar, $50 \mu \mathrm{m}$. b Statistics for the number of neurites of each recovered VSC4.1 motor neurons. n.s., non-significant. c Statistics for the length of neurites of each recovered VSC4.1 motor neurons (fold of OGD group). ${ }^{*} p<0.05,{ }^{* *} p<0.01$. $\mathbf{d}$-f Respectively, representative immunofluorescence images of Grp 78 protein, NF-KB protein, and BCl-xl protein of VSC4.1 motor neurons. GFP marked BMSCs. The white arrows show VSC4.1 motor neurons. Scale bars, $100 \mu \mathrm{m}$. g Representative images of TUNEL staining of VSC4.1 cells. Scale bar, $200 \mu \mathrm{m}$. h-j Respectively, quantification of Grp 78, NF-KB, and BCl-xl of VSC4.1 motor neurons (fold of OGD group). n.s., non-significant, ${ }^{* * *} p<0.0001$ vs OGD group. ${ }^{\#} p<0.05,{ }^{\# \#} p<0.01,{ }^{\# \# \# \# p<}$ 0.0001 vs Mock group. $\mathbf{k}$ Statistics of TUNEL positive rate of VSC4.1 cells. ${ }^{* *} p<0.01,{ }^{* * *} p<0.0001$ vs OGD group. ${ }^{\#} p<0.05,{ }^{\# \#} p<0.01$ vs Mock group 
(Fig. 4f, i) were decreased in the Over group but increased in the shRNA group. However, Grp 78 and NF$\mathrm{\kappa B}$ expressions in the three groups were significantly downregulated compared to the OGD group. The expression of the anti-apoptotic protein, Bcl-xl, significantly increased in both the Mock and Over groups, compared with the OGD or shRNA groups (Fig. 4f, j). Finally, we detected the cell apoptosis via TUNEL staining and results showed that apoptosis of VSC4.1 cell in the Over group significantly decreased, compared with the other three groups (Fig. 4g, k). In summary, CD157 overexpression in BMSCs can alleviate apoptosis and inflammation of injured motor neurons.

\section{Effects of CD157 on spinal cord neurons in vivo}

We operated in vivo BMSC-transplant surgeries after $\mathrm{SCI}$ on rats. The secondary injury tends to ease off at 7 days after SCI. At this time, inflammation and neuron regeneration begin to increase. Thus, we sampled and took freezing sections at 7 days after SCI (Fig. 5a). We
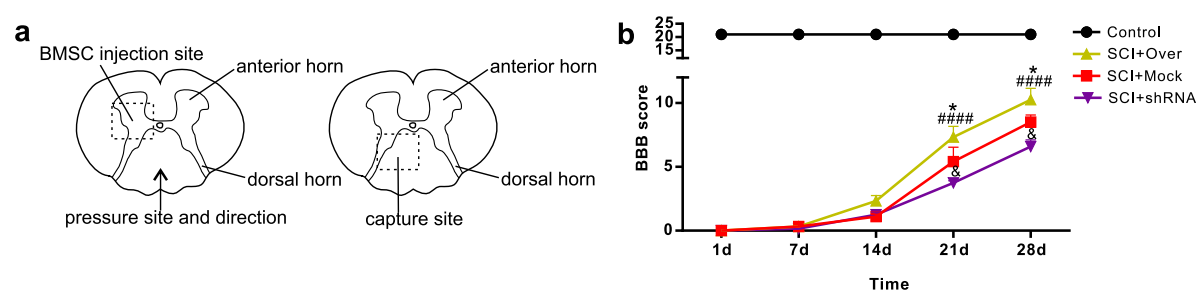

C

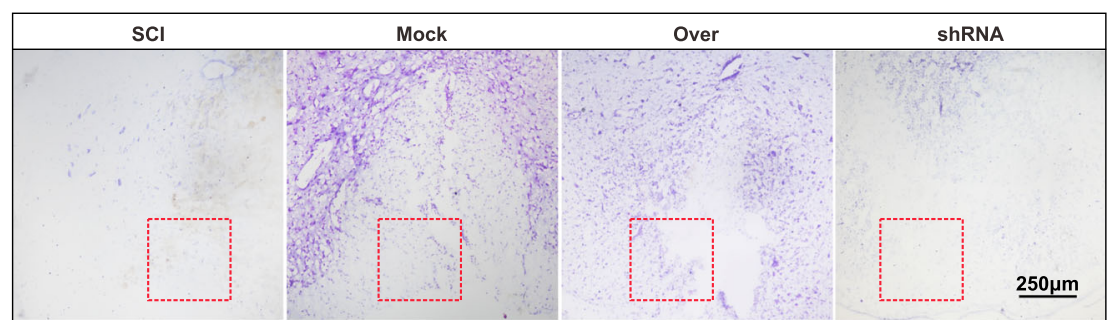

d
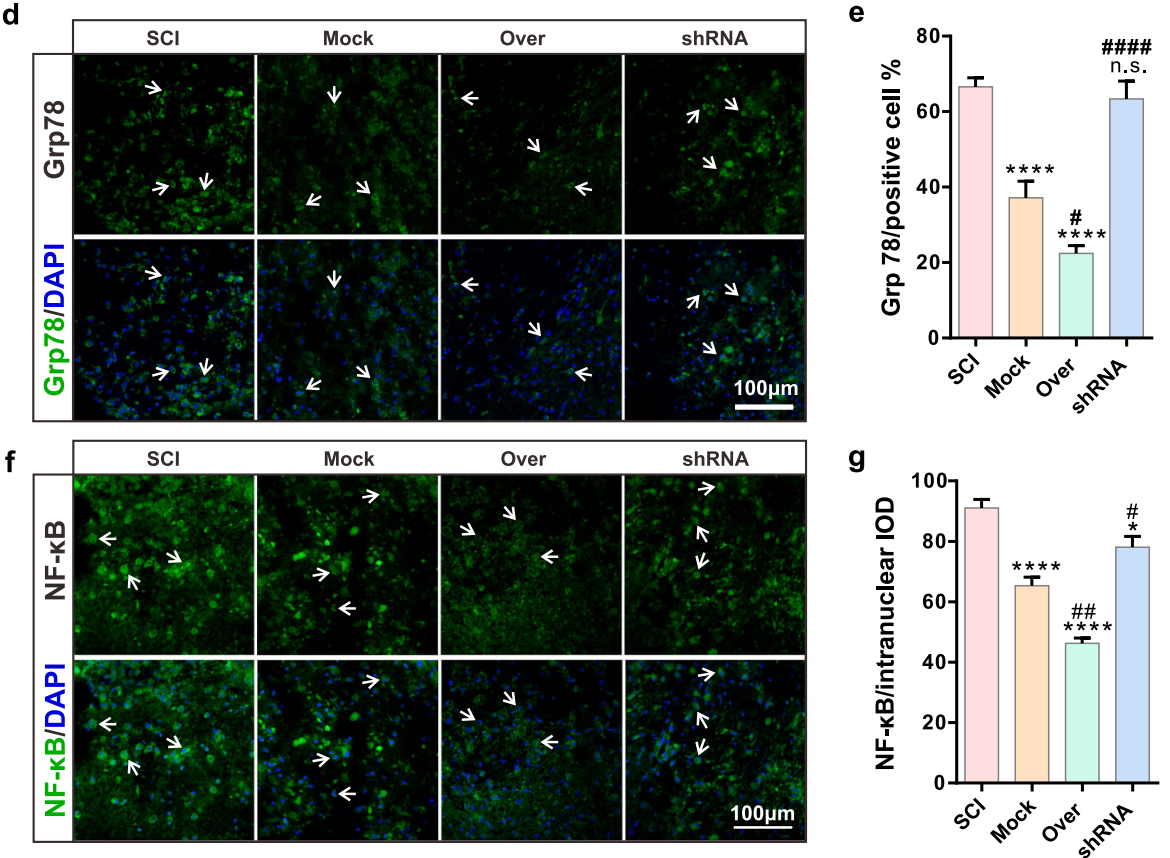

Fig. 5 CD157 overexpression in BMSCs attenuates inflammation and apoptosis of the injured neurons in vivo (1). a Schematic diagram of the spinal cord. b BBB scores of injured rats $(n=6)$. ${ }^{*} p<0.05,{ }^{\&} p<0.05$ vs SCl+Mock group; \#\#\# $p<0.001$ vs SCI+shRNA group. Representative $\mathbf{c}$ Nissl staining images of the spinal cord. The red rectangle showed the injured site. Scale bar, $250 \mu$ m. $\mathbf{d}$, f Representative immunofluorescence images of Grp 78 and NF-KB of neurons at the injured site. The white arrows indicate the positive cells. Scale bars, $100 \mu m$. e Statistics of Grp 78 positive

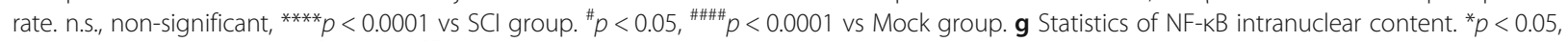
${ }^{* * * *} p<0.0001$ vs SCl group. ${ }^{\#} p<0.05,{ }^{\# \#} p<0.01$ vs Mock group 
assessed the motor function of the SCI rats. Our previous study demonstrated that normal BMSCs transplantation could facilitate rats' motor function recovery after SCI. We divided the rats into four groups: sham operation group (control), SCI+Mock group, SCI+Over group, and SCI+shRNA group. We used $\mathrm{BBB}$ scores to determine the paralysis severity caused by SCI, and the scores were significantly increased in the $\mathrm{SCI}+$ Over group and decreased in the $\mathrm{SCI}+$ shRNA group (Fig. 5b).

We used Nissl staining to study neuron protein synthesis and found that neurons were affected after SCI and BMSCs transplantation. There were more stained cell and deep color at the injured site in the Over group, indicating that protein synthesis enhanced in CD157 overexpressed group (Fig. 5c). We used immunofluorescence staining to detect protein expression and found Grp78 (Fig. 5d, e) and NF-kB (Fig. 5f, g) expressions were significantly decreased after overexpression transfected BMSC transplantation, while p-Akt (Fig. 6a, b) expressions increased in the Mock and Over groups. Meanwhile, the axon regeneration-related protein, GAP43, was upregulated in the Mock and Over groups, indicating that CD157 overexpression can promote neural regeneration (Fig. 6c, d). We also detected the cell apoptosis at the injured site by TUNEL staining and results showed that cell apoptosis significantly improved in Mock and Over groups (Fig. 6e, f). All above illustrated a

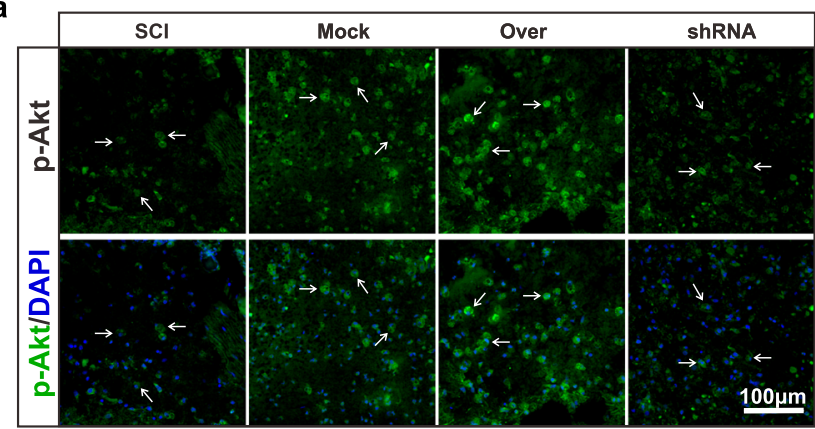

C

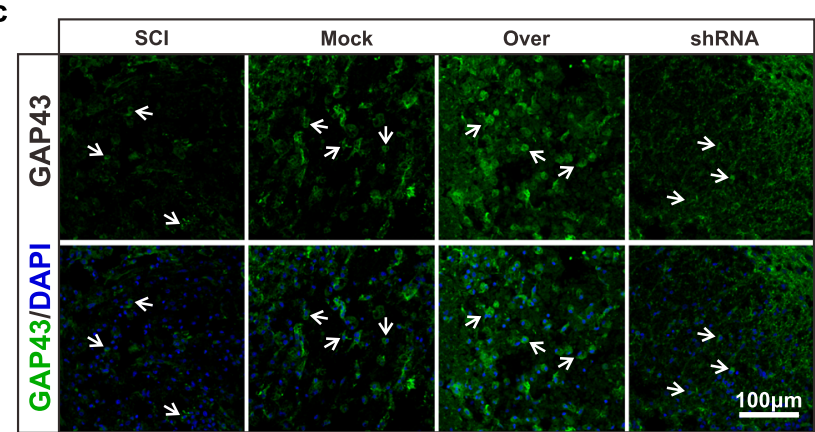

e

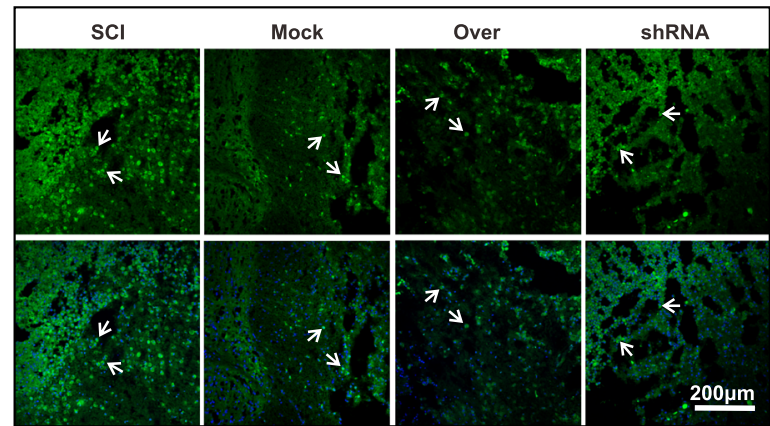

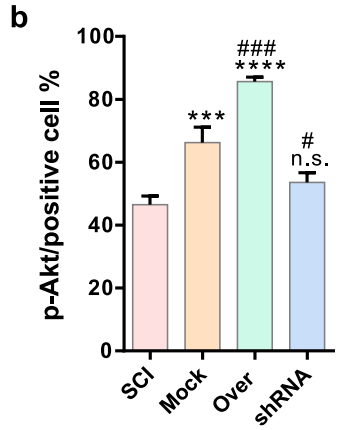

d

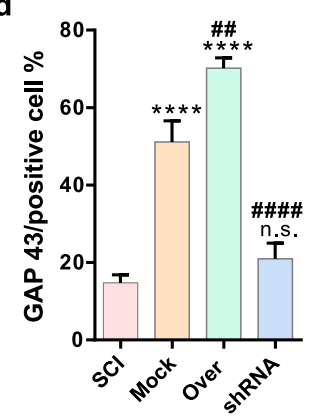

f

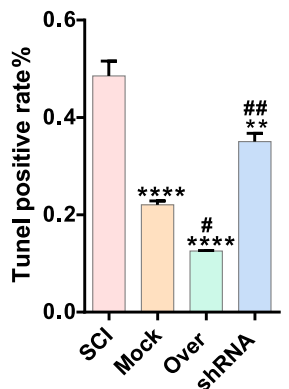

Fig. 6 CD157 overexpression in BMSCs attenuates inflammation and apoptosis of the injured neurons in vivo (2). a, c Representative immunofluorescence images of p-Akt and GAP 43 of neurons at the injured site. The white arrows indicate the positive cells. Scale bars, $100 \mu m$.

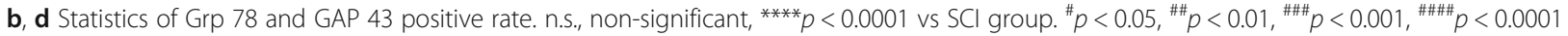
vs Mock group. e TUNEL staining images of neurons at the damage site. The white arrows indicate the positive cells. Scale bars, $200 \mu \mathrm{m}$. $\mathbf{f}$ Statistics of TUNEL positive rate. ${ }^{* *} p<0.01,{ }^{* * *} p<0.0001$ vs SCl group. ${ }^{\#} p<0.05,{ }^{\# \#} p<0.01$ vs Mock group 


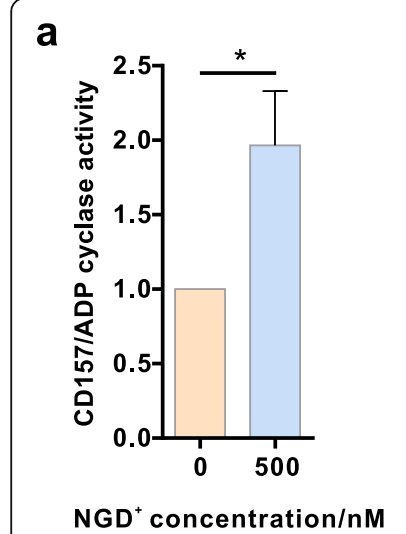

b

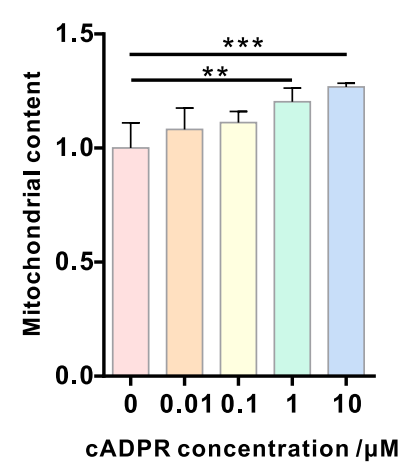

C

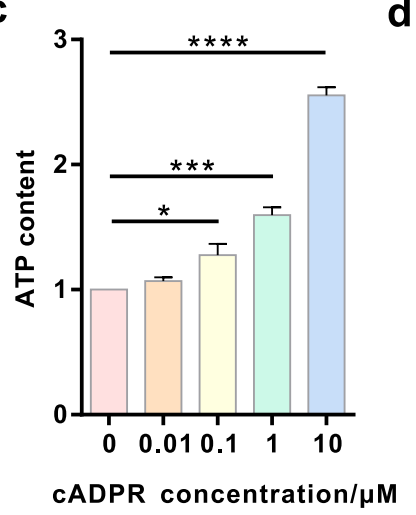

d

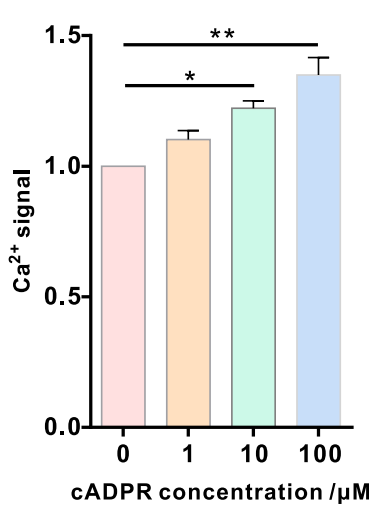

e

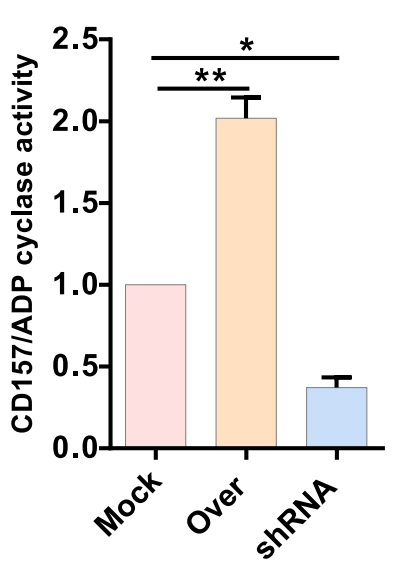

f

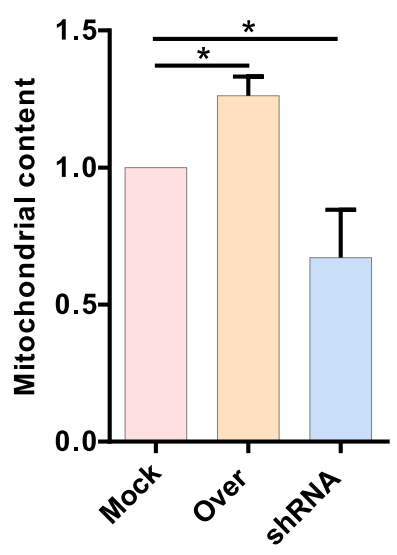

g

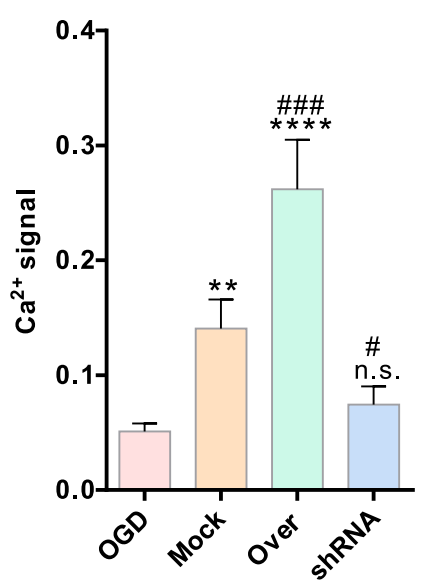

Fig. 7 CD157/ADPR-cyclase activity and $\mathrm{Ca}^{2+}$ signal in BMSCs. a Confirmation of CD157/ADPR-cyclase activity $(n=5$, fold of $0 \mathrm{nM})$. ${ }^{*} p<0.05$. b Statistics for the mitochondria content in BMSCs pre-stained using Mito Tracker Red CMXRos ( $n=5$, fold of 0 nM). ${ }^{* *} p<0.01,{ }^{* * *} p<0.001$. c Statistics for the ATP content in BMSCs subjected to CADPR at different concentrations $(n=3$, fold of $0 \mathrm{nM})$. ${ }^{*} p<0.05,{ }^{* * *} p<0.001$, ${ }^{* * * *} p<0.0001$. d Statistics for the $\mathrm{Ca}^{2+}$ signal in BMSCs subjected to CADPR at different concentrations ( $n=3$, fold of 0 nM). ${ }^{*} p<0.05$, ${ }^{* *} p<0.01$. e CD157/ADPRcyclase activity detect of different BMSCs ( $n=3$, fold of Mock group). ${ }^{*} p<0.05$, ${ }^{* *} p<0.01$. f Statistics for the mitochondria content in different BMSCs ( $n=3$, fold of Mock group). ${ }^{*} p<0.05$. g Statistics for the $\mathrm{Ca}^{2+}$ signal of transfected BMSCs when co-cultured with OGD VSC4.1 motor neurons ( $n=4$, fold of OGD group). n.s., non-significant, ${ }^{* *} p<0.01,{ }^{* * *} p<0.0001$ vs OGD group. ${ }^{\#} p<0.05,{ }^{\# \# \#} p<0.001$ vs Mock group

that CD157 upregulation can improve apoptosis and promote axon regeneration.

\section{BMSC CD157/ADPR-cyclase activity and $\mathrm{Ca}^{2+}$ signal}

CD157 is a member of the NADase/ADP-ribosyl cyclase family. We hypothesized that the CD157-cADPR-Ca ${ }^{2+}$ signaling pathway is involved in BMSC-derived extracellular mitochondria production and transfer. We determined BMSC enzymatic activity and found that CD157 has NADase activity (Fig. 7a). We further assessed if cADPR can regulate extracellular mitochondria production. The mitochondrion measurement (Fig. 7b) and detection of ATP content (Fig. 7c) of BMSCs demonstrated that ADPR-cyclase activity regulated the extracellular mitochondria production. Then, we evaluated the cADPR-Ca ${ }^{2+}$ signaling pathway and detected calcium levels in the BMSCs and result showed that calcium concentration increased with the increasing cADPR concentration (Fig. 7d). Then, we detected the $\mathrm{NGD}^{+}$ $(500 \mathrm{nM})$ treatment for various transfected BMSCs and found that BMSCs in the Over group presented highest ADP cyclase activity (Fig. 7e). Mitochondria content detect showed that BMSCs in the Over group produced more intracellular mitochondria than the other two groups (Fig. 7f). $\mathrm{Ca}^{2+}$ signal was also found to be highest in the Over group (Fig. 7g). Taken together, CD157cADPR-calcium could be a potential mechanism involved in BMSC-derived extracellular mitochondria production.

\section{Discussion}

SCI causes severe disabilities associated with motor dysfunction or paralysis and there are no effective treatment options. Secondary injury cascade, a complex, pervasive, 
and destructive pathological process causes a severely restricted axonal regeneration and functional recovery in SCI. Targeting a specific cascade is not an efficient therapeutic strategy because many related signaling pathways intersect and initiate other secondary injury events. Cellular energy production and metabolism take place in the mitochondrion. Mitochondrion can not only induce apoptosis but also play a key role in apoptosis [35]. Its trafficking is essential for neuronal survival, especially the axons and dendrites because of their energy demand and calcium flux [36]. Studies have reported that SCI causes mitochondria damage and disruption, by inducing oxidative stress reactions and cell apoptosis. Mitochondrial dysfunction is the initial step of neuronal injury that indirectly and directly promotes SCI pathology progression [37]. Some studies have therefore focused on the role of mitochondria in neuronal recovery and SCI treatment [38, 39]. Mitochondrial transplantation had significant benefits, including improved lower-limb locomotor function, suppressed regional endoplasmic reticulum stress, and mitochondriadependent apoptosis inhibition [37]. Mitochondrion can therefore be a potential candidate for SCI therapy. This study observed that a portion of BMSC-derived extracellular mitochondria is important, and ATP and MMP detection confirmed that extracellular mitochondria were functional. These could be the possible mitochondrial transfer mechanism to save damaged neurons. During co-culture, the functional mitochondria were transferred to VSC4.1 motor neurons and internalized. Moreover, the injured neurons were found to internalize more exogenous mitochondria than the normal cells for rescue.

The CD157 protein of BMSCs co-cultured with OGD neurons was upregulated, indicating that CD157can generate intracellular messengers in response to stimuli, catalyzing cADPR synthesis from $\mathrm{NAD}^{+}$[40]. cADPR is an important $\mathrm{Ca}^{2+}$-mobilizing cytosolic messenger [41] that provides the $\mathrm{Ca}^{2+}$ wave during fertilization [42], regulates dendritic cell functions [43], and contributes to airway disease [44]. $\mathrm{Ca}^{2+}$ signaling regulates some important mitochondrial activities, i.e., cytoplasmic $\mathrm{Ca}^{2+}$ concentration increase promotes mitochondrial ATP production $[45,46]$, and in turn, mitochondrial $\mathrm{Ca}^{2+}$ uptake regulates regulating the intracellular calcium signaling via buffering cytosolic $\mathrm{Ca}^{2+}$ levels $[46,47]$. Research has shown that CD38 mediates extracellular mitochondria transfer in astrocytes via calcium-dependent CD38/ cyclic ADP-ribose pathway, indicating that CD157 can regulate BMSC-derived extracellular mitochondria particle production and transfer.

There were elevated extracellular mitochondrial particle levels derived from the highly expressed CD157 in the modified BMSCs in separate cultures, indicating that CD157 regulates extracellular mitochondria production.
Besides, the high internalization of extracellular mitochondria occurred in the CD157 overexpressed groups, after co-culturing modified BMSCs and injured neurons, showing that CD157 upregulation could be the possible cause of the high-level internalization in damaged neurons.

The in vitro experiment results showed that the regenerative synapse length of neurons were longest in the CD157 high expression group, signifying that high mitochondria internalization promotes synaptic regeneration. In this study, Grp78, NF-kB, Bcl-xl, and Akt expressions were detected both in vivo and in vitro and the results showed that the Grp78 and NF- $k B$ expressions decreased, while Bcl-xl and p-Akt levels increased in the high CD157 group, indicating that apoptosis in the injured-cell decreases after CD157 upregulation in BMSCs. In addition, results of TUNEL detect both in vivo and in vitro directly illustrated the effect of CD157 upregulation in BMSCs on cell apoptosis. Nissl staining also indicated that the transplantation of CD157 overexpression BMSCs improved the synthesis of protein function of neurons. BBB scores also demonstrated that transplantation of the modified BMSC overexpression significantly improved the functional recovery of SCI rats.

To confirm whether the cADPR/calcium signaling pathway was involved in the process of producing and transferring mitochondria, ADPR-cyclase activity of CD157 and the mitochondria content, ATP content, and $\mathrm{Ca}^{2+}$ level in BMSCs treated with different concentration cADPR were measured. The cytoplasmic $\mathrm{Ca}^{2+}$, mitochondria, and ATP levels showed CADPR dependency. Consistently, the ADPR-cyclase activity, mitochondria content, and $\mathrm{Ca}^{2+}$ level presented difference in three transfected BMSCs and they were all highest in the Over group. Thus, we concluded that CD157 regulates mitochondrial production and transfer via the $\mathrm{CADPR}-\mathrm{Ca}^{2+}$ pathway.

In conclusion, CD157 upregulated in co-cultured BMSCs and the high CD157 expression increases extracellular mitochondria particle production and internalization via VSC4.1 motor neurons. CD157 upregulation in BMSCs inhibits cell apoptosis and promotes the recovery of neurons and motor functions both in vivo and in vitro. However, how the SCI environment stimulates the upregulation of CD157 in BMSCs and the signaling pathways involved in this process are unknown.

\section{Conclusion}

The present study for the first time demonstrated that CD157 on BMSCs might be stimulated by the microenvironment with injured neurons. In turn, upregulation of CD157 on BMSCs could increase the produce and transfer of mitochondria from BMSCs to injured 
neurons, improving the neuroregeneration and cell apoptosis. The calcium-dependent CD157/cyclic ADPribose signaling pathway may be involved in the mitochondria transfer from BMSCs to injured neurons of SCI rats and OGD-treated VSC4.1 motor neurons. The results suggested a novel approach for the efficiency of stem cell therapy strategies on SCI.

\section{Abbreviations}

SCl: Spinal cord injury; BMSCs: Bone marrow mesenchymal stem cells; ATP: Adenosine triphosphate; OGD: Oxygen-glucose deprivation; MMP: Mitochondrial membrane potential; NAD: Nicotinamide adenine dinucleotide; NGD: Nicotinamide guanine dinucleotide; ADP: Adenosinediphosphate; CADPR: Cyclic ADP-ribose; ER: Endoplasmic reticulum; BBB: Basso, Beattie and Bresnahan; BCM: BMSC-conditioned medium; MdBCM: Mitochondria deleted BMSC-conditioned medium; FACS: Fluorescenceactivated cell sorting; CFSE: Carboxyfluorescein succinimidyl ester; DAPI: 2-(4Amidinophenyl)-6-indolecarbamidine dihydrochloride; IOD: Integrated optical density

\section{Acknowledgements}

This study was supported by the National Natural Science Foundation of China (81871845) and Zhejiang Provincial Department of science and technology (LGD21H090003). Thanks for the technical support provided by the core facilities, Zhejiang University School of Medicine.

\section{Authors' contributions}

$\mathrm{ZX}$ and $\mathrm{HC}$ contributed to the experimental conceptualization and design. JL contributed to the experimental conceptualization and design, performed the most experiments and the statistics, and was a major contributor in writing the manuscript. HL performed the observation of extracellular mitochondria particles by transmission electron microscopy and motor functional detection. SC and SB performed partial experiments and provided considerable manuscript review. All authors read and approved the final manuscript.

\section{Funding}

The National Natural Science Foundation of China (81871845), Zhejiang Provincial Department of science and technology (LGD21H090003) and the Taizhou Science and Technology Project (20ywb98) supported this study.

\section{Availability of data and materials}

The datasets used and/or analyzed during the current study are available from the corresponding author on reasonable request.

\section{Declarations}

\section{Ethics approval and consent to participate}

All experimental procedures were approved by the Animal Ethics Committee of Zhejiang University and followed the National Institutes of Health guidelines strictly.

\section{Consent for publication \\ Not applicable.}

\section{Competing interests}

The authors declare that they have no competing interests.

\section{Author details}

'Department of Anatomy, School of Medicine, Zhejiang University, Hangzhou 310058, China. ${ }^{2}$ Department of Anatomy, Taizhou University; School of Medicine, Zhejiang University, 310058 Hangzhou, China. ${ }^{3}$ Department of Emergency Medicine, Sir Run Run Shaw Hospital; School of Medicine, Zhejiang University, Hangzhou 310058, China.
Received: 21 December 2020 Accepted: 22 March 2021

Published online: 17 May 2021

\section{References}

1. Ahuja CS, Nori S, Tetreault L, Wilson J, Kwon B, Harrop J, Choi D, Fehlings MG. Traumatic spinal cord injury-repair and regeneration. Neurosurgery. 2017;80(3S):S9-S22. https://doi.org/10.1093/neuros/nyw080.

2. Turtle JD, Henwood MK, Strain MM, Huang YJ, Miranda RC, Grau JW. Engaging pain fibers after a spinal cord injury fosters hemorrhage and expands the area of secondary injury. Exp Neurol. 2019;311:115-24. https:// doi.org/10.1016/j.expneurol.2018.09.018.

3. Visavadiya NP, Patel SP, VanRooyen JL, Sullivan PG, Rabchevsky AG. Cellular and subcellular oxidative stress parameters following severe spinal cord injury. Redox Biol. 2016;8:59-67. https://doi.org/10.1016/j.redox.2015.12.011.

4. DiSabato DJ, Quan N, Godbout JP. Neuroinflammation: the devil is in the details. J Neurochem. 2016;139(Suppl 2):136-53. https://doi.org/10.1111/ jnc.13607.

5. Bartus K, Galino J, James ND, Hernandez-Miranda LR, Dawes JM, Fricker FR, Garratt AN, McMahon SB, Ramer MS, Birchmeier C, Bennett DLH, Bradbury EJ. Neuregulin-1 controls an endogenous repair mechanism after spinal cord injury. Brain. 2016;139(Pt 5):1394-416. https://doi.org/1 0.1093/brain/aww039.

6. Ahuja CS, Wilson JR, Nori S, Kotter MRN, Druschel C, Curt A, Fehlings MG. Traumatic spinal cord injury. Nat Rev Dis Primers. 2017;3(1):17018. https:// doi.org/10.1038/nrdp.2017.18

7. Riegger T, Conrad S, Liu K, Schluesener HJ, Adibzahdeh M, Schwab JM. Spinal cord injury-induced immune depression syndrome (SCI-IDS). Eur J Neurosci. 2007:25(6):1743-7. https://doi.org/10.1111/j.1460-9568.2007.05447.x.

8. Brommer B, Engel O, Kopp MA, Watzlawick R, Muller S, Pruss H, et al. Spinal cord injury-induced immune deficiency syndrome enhances infection susceptibility dependent on lesion level. Brain. 2016;139(Pt 3):692-707. https://doi.org/10.1093/brain/awv375.

9. Rong H, Zhao Z, Feng J, Lei Y, Wu H, Sun R, Zhang Z, Hou B, Zhang W, Sun $Y E, G u X, M a Z$, Liu Y. The effects of dexmedetomidine pretreatment on the pro- and anti-inflammation systems after spinal cord injury in rats. Brain Behav Immun. 2017;64:195-207. https://doi.org/10.1016/j.bbi.2017.03.006.

10. Baptiste DC, Fehlings MG. Pharmacological approaches to repair the injured spinal cord. J Neurotrauma. 2006;23(3-4):318-34. https://doi.org/10.1089/ neu.2006.23.318

11. Ping X, Jiang K, Lee SY, Cheng JX, Jin X. PEG-PDLLA micelle treatment improves axonal function of the corpus callosum following traumatic brain injury. J Neurotrauma. 2014;31(13):1172-9. https://doi.org/10.1089/neu.2 013.3147.

12. Madathil SK, Saatman KE. IGF-1/IGF-R signaling in traumatic brain injury: impact on cell survival, neurogenesis, and behavioral outcome. In: Kobeissy FH, editor. Brain neurotrauma: molecular, neuropsychological, and rehabilitation aspects. Boca Raton: Frontiers in Neuroengineering; 2015.

13. Scholpa NE, Schnellmann RG. Mitochondrial-based therapeutics for the treatment of spinal cord injury: mitochondrial biogenesis as a potential pharmacological target. J Pharmacol Exp Ther. 2017;363(3):303-13. https:// doi.org/10.1124/jpet.117.244806.

14. Jia ZQ, Li G, Zhang ZY, Li HT, Wang JQ, Fan ZK, et al. Time representation of mitochondrial morphology and function after acute spinal cord injury. Neural Regen Res. 2016;11(1):137-43. https://doi.org/1 0.4103/1673-5374.175061.

15. McEwen ML, Sullivan PG, Rabchevsky AG, Springer JE. Targeting mitochondrial function for the treatment of acute spinal cord injury. Neurotherapeutics. 2011;8(2):168-79. https://doi.org/10.1007/s13311011-0031-7.

16. Wallner C, Huber J, Drysch M, Schmidt SV, Wagner JM, Dadras M, Dittfeld S, Becerikli M, Jaurich H, Lehnhardt M, Behr B. Activin receptor 2 antagonization impairs adipogenic and enhances osteogenic differentiation in mouse adipose-derived stem cells and mouse bone marrow-derived stem cells in vitro and in vivo. Stem Cells Dev. 2019;28(6):384-97. https:// doi.org/10.1089/scd.2018.0155.

17. Sivasubramaniyan $K$, llas DC, Harichandan A, Bos PK, Santos DL, de Zwart P, Koevoet WJLM, Owston H, Bühring HJ, Jones E, van Osch GJVM. Bone marrow-harvesting technique influences functional heterogeneity of mesenchymal stem/stromal cells and cartilage regeneration. Am J Sports Med. 2018;46(14):3521-31. https://doi.org/10.1177/0363546518804807. 
18. Patterson TE, Boehm C, Nakamoto C, Rozic R, Walker E, Piuzzi NS, Muschler GF. The efficiency of bone marrow aspiration for the harvest of connective tissue progenitors from the human iliac crest. J Bone Joint Surg Am. 2017; 99(19):1673-82. https://doi.org/10.2106/JBJS.17.00094.

19. Charbord P. Bone marrow mesenchymal stem cells: historical overview and concepts. Hum Gene Ther. 2010;21(9):1045-56. https://doi.org/10.1089/ hum.2010.115

20. Hu L, Wen Y, Xu J, Wu T, Zhang C, Wang J, du J, Wang S. Pretreatment with bisphosphonate enhances osteogenesis of bone marrow mesenchymal stem cells. Stem Cells Dev. 2017;26(2):123-32. https://doi.org/10.1089/scd.2016.0173.

21. Xu M, Wani M, Dai YS, Wang J, Yan M, Ayub A, Ashraf M. Differentiation of bone marrow stromal cells into the cardiac phenotype requires intercellular communication with myocytes. Circulation. 2004;110(17):2658-65. https:// doi.org/10.1161/01.CIR.0000145609.20435.36

22. Li H, Wang C, He T, Zhao T, Chen YY, Shen YL, Zhang X, Wang LL Mitochondrial transfer from bone marrow mesenchymal stem cells to motor neurons in spinal cord injury rats via gap junction. Theranostics. 2019;9(7):2017-35. https://doi.org/10.7150/thno.29400.

23. Morone S, Augeri S, Cuccioloni M, Mozzicafreddo M, Angeletti M, Lo Buono N, Giacomino A, Ortolan E, Funaro A. Binding of CD157 protein to fibronectin regulates cell adhesion and spreading. J Biol Chem. 2014; 289(22):15588-601. https://doi.org/10.1074/jbc.M113.535070.

24. Quarona V, Zaccarello G, Chillemi A, Brunetti E, Singh VK, Ferrero E, Funaro A, Horenstein AL, Malavasi F. CD38 and CD157: a long journey from activation markers to multifunctional molecules. Cytometry B Clin Cytom. 2013;84(4):207-17. https://doi.org/10.1002/cyto.b.21092.

25. Yamamoto-Katayama S, Sato A, Ariyoshi M, Suyama M, Ishihara K, Hirano T, et al. Site-directed removal of N-glycosylation sites in BST-1/CD157: effects on molecular and functional heterogeneity. Biochem J. 2001;357(Pt 2):38592. https://doi.org/10.1042/0264-6021:3570385.

26. Funaro A, Ortolan E, Bovino P, Lo Buono N, Nacci G, Parrotta R, et al. Ectoenzymes and innate immunity: the role of human CD157 in leukocyte trafficking. Front Biosci. 2009;14:929-43. https://doi.org/10.2741/3287.

27. Ishihara K, Hirano T. BST-1/CD157 regulates the humoral immune responses in vivo. Chem Immunol. 2000;75:235-55. https://doi.org/10.1159/000058772.

28. Ortolan E, Tibaldi EV, Ferranti B, Lavagno L, Garbarino G, Notaro R, Luzzatto L, Malavasi F, Funaro A. CD157 plays a pivotal role in neutrophil transendothelial migration. Blood. 2006;108(13):4214-22. https://doi.org/1 0.1182/blood-2006-04-017160.

29. Podesta M, Benvenuto F, Pitto A, Figari O, Bacigalupo A, Bruzzone S, et al. Concentrative uptake of cyclic ADP-ribose generated by BST-1+ stroma stimulates proliferation of human hematopoietic progenitors. J Biol Chem. 2005;280(7):5343-9. https://doi.org/10.1074/jbc.M408085200.

30. Higashida H, Liang M, Yoshihara T, Akther S, Fakhrul A, Stanislav C, Nam TS, Kim UH, Kasai S, Nishimura T, al Mahmuda N, Yokoyama S, Ishihara K, Gerasimenko M, Salmina A, Zhong J, Tsuji T, Tsuji C, Lopatina O. An immunohistochemical, enzymatic, and behavioral study of CD157/BST-1 as a neuroregulator. BMC Neurosci. 2017;18(1):35. https://doi.org/10.1186/s12868-017-0350-7.

31. Gu C, Li H, Wang C, Song X, Ding Y, Zheng M, Liu W, Chen Y, Zhang X, Wang L. Bone marrow mesenchymal stem cells decrease CHOP expression and neuronal apoptosis after spinal cord injury. Neurosci Lett. 2017;636:2829. https://doi.org/10.1016/j.neulet.2016.11.032.

32. Pu Y, Meng K, Gu C, Wang L, Zhang X. Thrombospondin-1 modified bone marrow mesenchymal stem cells (BMSCs) promote neurite outgrowth and functional recovery in rats with spinal cord injury. Oncotarget. 2017:8(56): 96276-89. https://doi.org/10.18632/oncotarget.22018.

33. Hayakawa K, Esposito E, Wang X, Terasaki Y, Liu Y, Xing C, Ji X, Lo EH. Transfer of mitochondria from astrocytes to neurons after stroke. Nature. 2016:535(7613):551-5. https://doi.org/10.1038/nature18928.

34. Rah SY, Park KH, Han MK, Im MJ, Kim UH. Activation of CD38 by interleukin8 signaling regulates intracellular Ca2+ level and motility of lymphokineactivated killer cells. J Biol Chem. 2005;280(4):2888-95. https://doi.org/10.1 074/jbc.M409592200.

35. Schapira AHV. Mitochondrial diseases. Lancet. 2012;379(9828):1825-34. https://doi.org/10.1016/s0140-6736(11)61305-6.

36. Schwarz TL. Mitochondrial trafficking in neurons. Cold Spring Harb Perspect Biol. 2013;5(6). doi: https://doi.org/10.1101/cshperspect.a011304.

37. Fang S-Y, Roan J-N, Lee J-S, Chiu M-H, Lin M-W, Liu C-C, Lam CF. Transplantation of viable mitochondria attenuates neurologic injury after spinal cord ischemia. J Thorac Cardiovasc Surg. 2019; https://doi.org/10.101 6/j.jtcvs.2019.10.151.
38. Zhu LL, Li MQ, He F, Zhou SB, Jiang W. Mitochondria targeted peptide attenuates mitochondrial dysfunction, controls inflammation and protects against spinal cord injury-induced lung injury. Cell Physiol Biochem. 2017; 44(1):388-400. https://doi.org/10.1159/000484919.

39. Scholpa NE, Williams H, Wang W, Corum D, Narang A, Tomlinson S, Sullivan PG, Rabchevsky AG, Schnellmann RG. Pharmacological stimulation of mitochondrial biogenesis using the Food and Drug Administration-approved beta2adrenoreceptor agonist formoterol for the treatment of spinal cord injury. J Neurotrauma. 2019;36(6):962-72. https://doi.org/10.1089/neu.2018.5669.

40. Graeff RM, Lee HC. Determination of ADP-ribosyl cyclase activity, cyclic ADPribose, and nicotinic acid adenine dinucleotide phosphate in tissue extracts. Methods Mol Biol. 2013;1016:39-56. https://doi.org/10.1007/978-1-62 703-441-8_4.

41. Guse AH. Second messenger function and the structure-activity relationship of cyclic adenosine diphosphoribose (CADPR). FEBS J. 2005;272(18):4590-7. https://doi.org/10.1111/j.1742-4658.2005.04863.x.

42. Tosca L, Glass R, Bronchain O, Philippe L, Ciapa B. PLCgamma, G-protein of the Galphaq type and CADPr pathway are associated to trigger the fertilization Ca2+ signal in the sea urchin egg. Cell Calcium. 2012;52(5):38896. https://doi.org/10.1016/j.ceca.2012.06.006.

43. Partida-Sanchez S, Goodrich S, Kusser K, Oppenheimer N, Randall TD, Lund FE. Regulation of dendritic cell trafficking by the ADP-ribosyl cyclase CD38: impact on the development of humoral immunity. Immunity. 2004;20(3): 279-91. https://doi.org/10.1016/s1074-7613(04)00048-2.

44. Deshpande DA, Guedes AGP, Graeff R, Dogan S, Subramanian S, Walseth TF, Kannan MS. CD38/CADPR signaling pathway in airway disease: regulatory mechanisms. Mediat Inflamm. 2018;2018:8942042-10. https://doi.org/10.11 55/2018/8942042

45. Rossi A, Pizzo P, Filadi R. Calcium, mitochondria and cell metabolism: a functional triangle in bioenergetics. Biochim Biophys Acta Mol Cell Res. 2019;1866(7):1068-78. https://doi.org/10.1016/j.bbamcr.2018.10.016.

46. Young KW, Bampton ET, Pinon L, Bano D, Nicotera P. Mitochondrial Ca2+ signalling in hippocampal neurons. Cell Calcium. 2008;43(3):296-306. https://doi.org/10.1016/j.ceca.2007.06.007.

47. Rizzuto R, De Stefani D, Raffaello A, Mammucari C. Mitochondria as sensors and regulators of calcium signalling. Nat Rev Mol Cell Biol. 2012;13(9):566-78. https://doi.org/10.1038/nrm3412.

\section{Publisher's Note}

Springer Nature remains neutral with regard to jurisdictional claims in published maps and institutional affiliations.

Ready to submit your research? Choose BMC and benefit from:

- fast, convenient online submission

- thorough peer review by experienced researchers in your field

- rapid publication on acceptance

- support for research data, including large and complex data types

- gold Open Access which fosters wider collaboration and increased citations

- maximum visibility for your research: over $100 \mathrm{M}$ website views per year

At $\mathrm{BMC}$, research is always in progress.

Learn more biomedcentral.com/submissions 